Dicenda. Estudios de lengua y literatura españolas

ISSN-e: 1988-2556

http://dx.doi.org/10.5209/DICE.62139

\title{
El estudio de las características sintácticas del discurso escrito
}

\author{
José M. Bustos Gisbert ${ }^{1}$
}

Recibido: 26 de julio de 2016 / Aceptado: 1 de marzo de 2017

Resumen. Este trabajo proporciona herramientas con las que desentrañar cómo usan los usuarios adultos y competentes las diferentes opciones sintácticas al configurar los enunciados de textos escritos. Desde la consideración del enunciado como unidad mínima de construcción textual, se persigue analizar cómo se construye sintácticamente. Para ello se fijan dos cuestiones: de un lado, las unidades sintácticas en las que se pueden formalizar los enunciados; de otro, los tipos de relación que pueden establecerse dentro ellas.

Palabras clave: texto escrito; unidades textuales; sintaxis del discurso; subordinación y discurso.

\section{[en] Analysis of the Syntactic Characteristics of Written Discourse}

\begin{abstract}
The objective of this article is to provide the tools needed to understand exactly how various syntactic options are used by competent adult writers to produce written texts. We shall consider the sentence as the smallest unit that can comprise a text and attempt to discern how these units are used in communicatively efficient ways. In order to fulfill this goal, this comprehensive research project seeks to address two main questions: on the one hand, what syntactic units can be used to establish sentences, and on the other, what kinds of relationships can be established within each syntactic unit.
\end{abstract}

Keywords: written text; textual units; discourse syntax; subordination and discourse analysis.

Sumario: 1. Introducción; 2. Estudios de madurez y complejidad sintáctica; 3. Análisis de la sintaxis del texto escrito; 4. Clasificación de subordinadas; 5. Conclusión.

Cómo citar: Bustos Gisbert, José M. (2018). El estudio de las características sintácticas del discurso escrito, en Dicenda. Estudios de Lengua y Literatura Españolas, 36, 89-114.

\section{Introducción}

En un texto clásico de los estudios de lingüística, Lyons (1968) afirma que la sintaxis estudia el modo en el que las palabras se combinan para formar oraciones. Es esta una definición perfectamente asumible hoy desde la perspectiva de la gramática descriptiva; tanto es así que entre ella y la propuesta en la Nueva Gramática de la Lengua Española (en adelante NGLE), publicada en 2009 por la Real Academia

\footnotetext{
1 Universidad de Salamanca jbustos@usal.es
} 
Española, apenas se aprecian diferencias: a la sintaxis le corresponde el análisis de la manera en que se combinan y se disponen linealmente las palabras, así como el de los grupos que forman $(\$ 1.1 \mathrm{a})^{2}$. Desde esta percepción de la disciplina, los esfuerzos se han volcado habitualmente en la descripción de las posibilidades combinatorias y relacionales de la lengua. El trabajo ha sido extenso, intenso y no exento de polémica en numerosas ocasiones. Fruto de ello, y solo en lo referido a la lengua española, la bibliografía es enorme en cantidad y en fecundidad. Sin embargo, ese interés (perfectamente justificado por otra parte) por ofrecer un modelo descriptivo exhaustivo no ha ido acompañado de una valoración referida a cuáles son las posibilidades sintácticas por las que nos decantamos en el uso real y cotidiano de la lengua.

Ciertamente, la descripción ubica todas las opciones sintácticas en el mismo nivel, sin considerar su rendimiento en el uso. Sin embargo, es ese rendimiento el que precisamente atañe a los estudios realizados desde una perspectiva discursiva, que es la que queremos adoptar. En el texto se plasma el uso de las herramientas lingüistas a disposición del hablante; nos interesa descubrir algunas de sus características sintácticas más sobresalientes y distintivas. El objetivo que nos marcaremos en el trabajo que aquí presentamos será proporcionar las herramientas con las que desentrañar cómo usamos las diferentes opciones sintácticas al configurar los enunciados en textos escritos y redactados por usuarios adultos y competentes. Tal objetivo nos impone aclarar cuestiones relativas tanto a las unidades como a los procedimientos de análisis, lo que supone, inevitablemente, repasar la naturaleza de unos y otros en las investigaciones que nos preceden.

Apoyaremos nuestras reflexiones en el estudio de un corpus de trabajo tomado de Corputrad y compuesto por 369 textos de entre 400 y 450 palabras redactados en los cursos 2012/2013 y 2013/2014 y correspondientes a cuatro modos del discurso: narración, descripción, exposición e instrucción ${ }^{3}$. En términos numéricos el corpus se resume de la siguiente manera:

2 Las referencias a epígrafes de la $N G L E$ se han realizado con el signo $\S$. Todas ellas remiten a la versión extendida del texto académico.

3 Corputrad es un corpus de textos escritos originalmente en español por estudiantes de primer curso del Grado en Traducción e Interpretación de la Universidad de Salamanca. En la actualidad reúne más de 4.500 textos redactados entre 2006 y 2015 por 600 informantes distintos y acumula aproximadamente tres millones de palabras. La fiabilidad del corpus está justificada en Bustos (2013b: 107): "Entendemos que la muestra es representativa desde dos perspectivas diferentes. La primera tiene que ver con su competencia escritora: en primer lugar, han tenido que efectuar una prueba de competencia mínima en expresión escrita en castellano para acceder a estos estudios; además, reciben instrucción específica en redacción de textos a lo largo de ese curso académico y en tres asignaturas distintas. La segunda perspectiva tiene que ver con la fiabilidad del grupo en términos sociolingüísticos. Así, exhiben una edad media entre 18 y 20 años, lo que les incluye en el grupo de usuarios adultos, y con una formación académica de nivel superior en tanto que todos son estudiantes universitarios. Se han analizado textos correspondientes a cuatro cursos académicos, y han sido redactados por (...) informantes (...) distribuidos en términos diatópicos de la siguiente manera: área correspondiente a las hablas meridionales, 11,8\%; modalidad leonesa, 43,25\%; modalidad aragonesa, 2,8\%; modalidad castellana, 24,71\%; dominio del gallego, 5.61\%; dominio del euskera, 10,67\%; y dominio del catalán, 1,12\%". Los textos utilizados para esta investigación formaron parte de la evaluación del curso universitario en el que estaban matriculados los 160 informantes y fueron redactados en el aula. Para ser sometidos a análisis y con el fin de garantizar que se trata de autores competentes en expresión escrita, solo se han valorado aquellos ejercicios que obtuvieron una nota igual o superior a 6 , en una escala de 6 a 10 , y que fueron escritos por estudiantes cuya lengua materna es el castellano. 


\begin{tabular}{|c|c|c|c|c|c|c|}
\hline & \multicolumn{2}{|c|}{$2012 / 13$} & \multicolumn{2}{|c|}{$2013 / 14$} & \multirow{2}{*}{$\begin{array}{c}\text { Total } \\
\text { de textos }\end{array}$} & \multirow{2}{*}{$\begin{array}{c}\text { Total } \\
\text { de palabras }\end{array}$} \\
\hline & Textos & Palabras & Textos & Palabras & & \\
\hline Narrativo & 38 & 12.285 & 35 & 13.369 & 73 & 25.654 \\
\hline Descriptivo & 48 & 19.539 & 54 & 23.731 & 102 & 43.270 \\
\hline Instructivo & 40 & 16.175 & 48 & 22.751 & 88 & 38.926 \\
\hline Expositivo & 49 & 19.552 & 57 & 25.120 & 106 & 44.672 \\
\hline TOTAL & 175 & 67.551 & 194 & 84.971 & 369 & 152.522 \\
\hline
\end{tabular}

\section{Estudios de madurez y complejidad sintáctica}

Las investigaciones precedentes relativas a la naturaleza sintáctica del texto escrito ya han dado frutos ciertamente interesantes, aun cuando se han asumido puntos de vista muy distintos. Uno de los posibles acercamientos supone abordar la cuestión desde una perspectiva psicolingüística vinculada a los estudios del discurso y que entronca con las investigaciones relativas a los procesos de comprensión de la lectura. Es el caso de Berko y Bernstein (1998/2001), que se fijan específicamente en el procesamiento de oraciones. Sostienen que el lector necesita de mayor tiempo de comprensión cuantas más construcciones subordinadas tiene una oración; según ellos, la resolución sintáctica es necesaria para poner en marchar el proceso de aprehensión. Por todo ello, si la estructura sintáctica es compleja, los destinatarios necesitan que se hagan pausas entre cláusulas para que les dé tiempo a asimilar el contenido Y es que en el procesamiento de las oraciones funcionamos con la memoria a corto plazo: el componente básico en el almacenamiento es la proposición, que es la unidad mínima de información, pero no todas se procesan igual, de manera que, cuanta más complejidad sintáctica, que se traduce en el uso de más subordinadas, más susceptibles son de ser procesadas incorrectamente o, simplemente, de no ser procesadas. El excelente trabajo de Masi (2003) realiza un exhaustivo análisis de diversos estudios que se han acercado a la cuestión desde esta perspectiva

Desde una posición estrictamente lingüística también se han llevado a cabo estudios ciertamente interesantes referidos a la complejidad lingüística de los textos. Con todo, es importante destacar que se insertan en una tradición investigadora que parte de una hipótesis alejada de nuestros objetivos: la complejidad sintáctica de la forma expresiva de los hablantes aumenta a media que lo hacen la edad y la instrucción ${ }^{4}$.

Casi todos parten de las investigaciones de Hunt (1965), quien aplica una perspectiva generativa a sus estudios acerca de la naturaleza de las redacciones escritas por niños de 4, 8 y 12 años: asocia la madurez sintáctica a la capacidad de construir oraciones más complejas mediante transformaciones sintácticas. El hecho de estudiar la escritura infantil le lleva a identificar unidades de análisis ciertamente novedosas y justificadas desde la naturaleza de los informantes. Se trata de las denominadas Unidades Terminales (UT): las concibe como herramienta para superar los

4 Crespo, Alfaro y Góngora (2011) resumen perfectamente el estado de la cuestión. Los autores clasifican los estudios de complejidad según se hayan realizado desde tres enfoques que denominan tradicionalista, generativista y funcional discursivo. 
problemas de puntuación y del alargamiento constante por coordinación detectados en la escritura infantil.

La línea trazada por Hunt ha tenido una notable continuidad en lo que concierne a la lengua española. Así, Véliz (1986 y 1988) efectúa una adaptación de sus presupuestos a nuestro idioma. Sus conclusiones están asociadas a las diferencias en las estructuras sintácticas utilizadas por cada grupo de estudio, al crecimiento sintáctico que se puede deducir en los escritores a partir de tales diferencias y a las estructuras de dominio tardío. Cabe señalar que su estudio solo tiene en cuenta textos de naturaleza narrativa y no considera ningún factor de naturaleza sociolingüística. No obstante, ha reconocido la importancia de variables de esta naturaleza en trabajos posteriores: Véliz (1999) parte de la hipótesis de que la complejidad sintáctica depende entre otros factores de la edad y del nivel de instrucción; por su parte, Véliz (2004) evalúa los efectos del envejecimiento en el procesamiento sintáctico. Ya en España es obligado recordar los trabajos de Torres González (1993 y 1994): a partir de las propuestas de Véliz, la autora aporta alguna novedad interesante, pues analiza el efecto de variables de naturaleza sociolingüística como el género textual, el tipo de centro educativo y el nivel sociocultural de las familias de los informantes.

En una línea de naturaleza funcional discursiva se integra otra serie de investigaciones ciertamente interesantes. Dentro de ella cabe distinguir a su vez dos direcciones. La primera establece las diferencias de complejidad sintáctica no tanto en relación con la madurez y las condiciones sociolingüísticas en las que se ubican los usuarios, sino desde la naturaleza diafásica de las producciones, planteando diferencias entre sintaxis oral y escrita. Uno de los más exhaustivos es el estudio de Castellá (2001). En él persigue comparar la complejidad sintáctica de la lengua hablada y la lengua escrita. Parte de un corpus de tres grupos de textos (conversación informal, clase magistral y prosa académica escrita), que analiza desde una perspectiva tradicional de la gramática a la hora de establecer unidades y procedimientos. Trabaja sobre la base de las oraciones e identifica tres tipos de relaciones: coordinación, subordinación e interordinación. En lo referido a la primera, distingue coordinación sintagmática y clausal, que, a su vez, podrá ser intraoracional o extraoracional; dentro de la primera, solo incluye las copulativas y las disyuntivas. Por lo que afecta a la subordinación, distingue tres grupos: sustantivas, adjetivas (limitadas a las de relativo) y adverbiales, dentro de las cuales considera las siguientes: locativas, temporales, modales, comparativas y consecutivas discontinuas. Finalmente, propone reconocer, a partir de Cuenca (1991) y Badía (1994), la existencia de oraciones interordinadas. Se trataría de una relación de tipo intermedio donde ubicar construcciones que no son de equivalencia, pero tampoco de dependencia o inclusión, por lo que comparten en una proporción variable de características comúnmente atribuidas a la coordinación y la subordinación. Con ellas da solución al tradicional problema de las adverbiales impropias: condicionales, causales, ilativas y finales. También incluye en este grupo las adversativas porque no cumplen, como las restantes coordinadas, los criterios de simetría y reversibilidad.

La segunda línea centra su atención en evaluar la complejidad sintáctica asociada a los modos del discurso. Dentro de ella, un buen grupo de investigadores ha partido de los presupuestos desarrollados por Hunt. Así, Torres González (1997) ha analizado la complejidad en dos modos del discurso (narrativo y descriptivo) y para ello parte de la obra de ocho escritores canarios; de cada uno de ellos selecciona dos textos por modalidad discursiva de unas 200 palabras. Por su parte, Véliz (1999) analiza 60 fragmentos de 300/350 palabras 
correspondientes a tres modos discursivos: narrativo, descriptivo y argumentativo; concluye que el discurso argumentativo es más complejo en extensión de cláusulas, número de subordinadas y número de incrustaciones clausulares. Baers y Nagy (2009) asocian la complejidad sintáctica a la estructura clausal: en los textos expositivos la complejidad es intraclausal y se asocia al uso de grupos nominales más extensos; en cambio, en las narraciones es interclausal. Meneses y Ow (2012) asocian el estudio de la complejidad sintáctica a la teoría de los géneros del discurso, específicamente en la línea propuesta por Batjin (1982). Finalmente, Muse y Delicia (2013) llevan a cabo un trabajo que quiere evaluar cuáles son las causas que motivan la falta de pericia de los estudiantes universitarios a la hora de redactar textos de naturaleza expositiva/argumentativa. Terminan por vincular la mayor complejidad sintáctica a dos variables, como son la alfabetización (grado de instrucción de los hablantes) y lo que denominan literacidad, según los usuarios hayan o no recibido formación específica en capacidades asociadas a la escritura ${ }^{5}$.

Por otra dirección, se ha intentado superar las unidades de trabajo propuestas por Hunt. En ese sentido, son muy interesantes las aportaciones de Berman y Nir-Sajiv (2009), que se centran en el estudio de los roles de las estructuras sintácticas en la construcción de los discursos y en la valoración de la complejidad sintáctica según los tipos de textuales. Por su parte, Nir y Berman (2010) plantean acercarse a los estudios de complejidad desde una perspectiva cognitiva y funcional, pero también discursiva al asumir la importancia de los canales y el tipo de interacción. Además, proponen nuevas unidades de análisis ${ }^{6}$. En el caso del texto escrito renuncian al párrafo porque es impreciso y también al concepto de oración porque es un constructo gramatical. Como alternativa proponen la cláusula y el paquete clausular (PC) ${ }^{7}$. La primera se define con criterios sintácticos y semánticos: se trata de una predicación que expresa una situación simple. La segunda es la unidad textual mínima marcada por criterios sintácticos, discursivos y temáticos en la escritura. En el caso del PC, que será su unidad básica de trabajo, distinguen cinco opciones según como se relacionan las cláusulas que lo componen:

- Isotaxis: Cláusulas aisladas, sin nexos entre ellas.

- Parataxis simétrica: cláusulas de equivalencia informativa. Construidas por yuxtaposición o por nexos de coordinación.

- Parataxis asimétrica: Cláusulas que dependen parcialmente de la principal: a mitad de camino de la hipotaxis. Incluyen las coordinadas y yuxtapuestas de verbo elíptico y las subordinadas sustantivas de complemento directo, atributo o complemento predicativo.

- Hipotaxis: Cláusulas que dependen de la principal: adjetivas especificativas, sustantivas en función de sujeto, adverbiales propias (tiempo, modo y lugar), concesivas, consecutivas, causales, finales, condicionales y comparativas.

- Endotaxis: Cláusulas incrustadas: se trata de las adjetivas explicativas, las adverbiales en aposición y las reparadoras en función parentética ${ }^{8}$.

5 Por otros caminos se han aplicado los presupuestos de Hunt al aprendizaje el español como lengua extranjera. Es el caso de Bartolomé (2009), quien asocia la madurez sintáctica a la capacidad de los estudiantes a la hora de integrar sintácticamente su uso del idioma. Por su parte, Mavron (2013) compara las estructuras sintácticas usadas por cinco hablantes de español L1 y 44 aprendices griegos de nivel B1.

Véase también Berman y Katzenberger (2004).

Los conceptos de cláusula y paquete clausular tienen su origen en Katzenberger (2004).

Las atractivas propuestas grupo de trabajo liderado por Ruth Berman en la Universidad de Tel Aviv han sido adaptadas al español por Meneses, Ow y Benítez (2012). 


\section{Análisis de la sintaxis del texto escrito}

Los trabajos que hemos recordado en las páginas precedentes asocian complejidad sintáctica a madurez y vinculan la simplicidad con la preferencia por la oración simple y por la parataxis. Sin embargo, como bien apunta Narbona (1996), no se ha demostrado que esas construcciones sean necesariamente las más simples. De hecho, la sencillez sintáctica no es algo fácilmente demostrable. Hay, además, en los estudios realizados desde tal premisa, un sesgo que tiende a valorar la expresión sintácticamente más compleja como síntoma de madurez lingüística, de donde se colige que esa forma expresiva es más rica.

Sin embargo, los términos complejidad y madurez resultan en nuestra percepción muy imprecisos a la vez que ineficaces, entre otras cosas porque carecemos de la definición de un determinado estándar que permita fijar algún tipo de comparación. Por ello, creemos que el objetivo no ha de ser evaluar si un modelo expresivo es más complejo que otro ni tampoco desentrañar qué factores han de considerarse en el momento de identificar un grado de complejidad.

Asimismo, hemos de considerar que en esos trabajos detectamos ciertas insuficiencias tanto en las unidades de las que parten como en las taxonomías sintácticas utilizadas en el análisis, que pueden resultar injustificadas en algunos casos e incompletas en otros. Dedicaremos las páginas siguientes a ambas cuestiones.

\subsection{Unidades}

Debemos considerar que ni las Unidades Terminales (UT) ni los Paquetes Clausulares (PC) ni las Cláusulas son unidades del discurso. Su aportación, interesantísima por otra parte, tiene su origen en las dificultades que padecieron los investigadores que las propusieron a la hora de identificar las unidades textuales. Sin embargo, consideramos que la aproximación al análisis ha de ser de naturaleza estrictamente discursiva. Por tanto, entendemos que la unidad de estudio también debe serlo. Para ello volveremos a investigaciones precedentes referidas a los límites, la naturaleza y la función de las unidades del discurso que presentamos en Bustos Gisbert (2013a). Estas parten en lo esencial de algunas de las propuestas más habitualmente suscritas en la actualidad y en las que se defiende que no han de confundirse las unidades textuales con las sintácticas porque suponen niveles de análisis diferentes. Parecen, por tanto, ya superadas las percepciones en las que se interpreta el texto como unidad superior a la oración. En ese sentido, cabe recordar la propuesta de Fuentes (2014: 138): "construimos los mensajes con oraciones y palabras, pero consideradas desde la producción generan enunciados y textos". A partir de ahí, sugiere la existencia de dos sistemas de unidades que responden a dos opciones metodológicas. Una analiza la comunicación desde el sistema lingüístico y es de naturaleza microestructural, pues su base de análisis es la oración; desde ella las unidades de trabajo son, de mayor a menor, la oración, el sintagma, la palabra o lexía, el morfema y el sema o el fonema. Otra lo hace desde la perspectiva pragmática del uso; supone una postura macroestructural en la que el objeto de estudio es discursivo y las unidades de análisis son el texto, la secuencia, el párrafo y el enunciado. Así pues, los enunciados son las unidades discursivas mínimas: son actos enunciativos y realizan un acto de habla (Fuentes, 2014), están dotados de independencia sintáctica y autonomía semántica (Gutiérrez Ordóñez, 1984/1997), y transmiten al menos una información temática 
y otra remática (Pastor, 2008). El enunciado es, pues, una realización comunicativa contextualizada que tiene su correlato formal/estructural en oraciones o en unidades menores. No nos comunicamos con oraciones sino con enunciados, que son unidades mínimas de comunicación y pueden estar representados por oraciones, pero también por otras unidades no oracionales.

Los límites de los enunciados vienen fijados en el caso del discurso oral por la entonación (Fuentes, 2014). En la lengua escrita se establecen mediante la puntuación. Según De Beaugrande (1984), esta es un subsistema discursivo que marca unidades y subunidades textuales y, con ello, fija jerarquías y establece prioridades. En el mismo sentido, Ferreiro (1996) sostiene que las marcas de puntuación son de naturaleza heterogénea: algunas, como las interrogaciones y las exclamaciones, tienen valor suprasegmental; pero esto no ocurre con todas. De hecho, normalmente los signos no reflejan la prosodia, sino que fijan unidades textuales de procesamiento informativo. Por ello, Figueras (1999 y 2001) afirma que cada signo se asociaría a una unidad distinta. Su propuesta es muy atractiva, pero despierta ciertas dudas a la hora de establecer las unidades del discurso: algunas tienen que ver con cómo distinguimos desde una perspectiva textual los enunciados, las cláusulas textuales y los enunciados oracionales. Otras se refieren a si la oración o el sintagma son, como propone, unidades del discurso.

A partir de todo lo apuntado, parece posible afirmar que la puntuación cumple, entre otros, un papel esencial en el momento de fijar los límites de los enunciados en los textos de naturaleza escrita. Estos están delimitados por aquellos signos de puntuación que indican o pueden indicar el final de períodos sintácticamente independientes: el punto y seguido, el punto y aparte, el punto y coma, los dos puntos, los signos de admiración e interrogación, los paréntesis y los guiones.

\subsection{Taxonomía}

Por lo que afecta a la consistencia de las taxonomías de análisis, las recogidas en las distintas propuestas resultan en general insatisfactorias desde dos perspectivas: ninguna considera unidades inferiores a la oración y resultan categorialmente discutibles. Nos centraremos ahora en la segunda de estas insuficiencias

Todos los trabajos que emanan más o menos explícitamente de los postulados de Hunt lo hacen asumiendo dos cuestiones ciertamente polémicas. En primer lugar, se establece un contraste taxonómico entre oraciones coordinadas y subordinadas, aunque está comprobado que la coordinación es un fenómeno sintáctico que puede darse dentro de la subordinación. En segundo término, se postula una clasificación de las subordinadas en sustantivas, adjetivas y adverbiales aun cuando esta distinción es más que discutible hasta el punto de que en la actualidad solo se acepta sin restricciones la existencia de las primeras. La NGLE limita las adjetivas a las subordinadas de relativo, más específicamente a aquellas que presentan un antecedente expreso (§1.13o); y en cuanto a las adverbiales o circunstanciales afirma que es el grupo "más polémico de los tres, hasta el punto de que son raras las gramáticas modernas que les dan cabida como unidades de análisis sintáctico" (§1.13p).

Por su parte, la clasificación de Nir y Berman referida a las relaciones sintácticas y la arquitectura interclausular establece cinco categorías en cuya definición se aplican en unos casos criterios sintácticos y en otros, semánticos. Así, por ejemplo, la isotaxis se distingue de la parataxis simétrica por un criterio formal: el uso o no de 
nexos entre cláusulas; en cambio, la parataxis asimétrica, la hipotaxis y la endotaxis establecen a veces una diferencia más informativa que formal, hasta el punto de que en las primeras se establecería una dependencia semántica parcial de una cláusula respecto de otra; resultado de ello, se incluyen en ese grupo construcciones formalmente tan diversas como las coordinadas y las yuxtapuestas de verbo elíptico, las subordinadas sustantivas de complemento directo y las construcciones atributivas y predicativas. Por su parte en la hipotaxis, donde la dependencia es total, se incluyen las subordinadas sustantivas de sujeto, las adjetivas especificativas y las adverbiales propias (así denominadas en dichos trabajos). Finamente, al definir la endotaxis parece que vuelven a un criterio formal, pues se indica que se trata de una relación en la que una cláusula se incrusta dentro de otra; dentro de ellas consideran las adjetivas explicativas y las subordinadas adverbiales en aposición.

Finalmente, la taxonomía propuesta por Castellá (2001) se construye sobre la base de distinguir oraciones coordinadas, subordinadas e interordinadas. Dentro de las primeras, se ve en la necesidad de identificar coordinaciones extraoracionales, concepto que supera con creces los límites de la gramática tradicional, que parece suscribir, para solucionar la paradoja de supuestas coordinaciones que excederían los márgenes del enunciado textual. En cambio, en lo que toca a las subordinadas, parte de la posición gramatical más tradicional que distingue entre subordinadas sustantivas, adjetivas y adverbiales.

La mayor novedad de su propuesta consiste en proponer un tercer grupo de construcciones que denomina interordinadas. El concepto de interordinación, que ha sido ampliamente expuesto por Moya (1996 y 2005), es heredero del de bipolaridad, desarrollado por Rojo (1978: 104), quien afirma que "podemos llamar, en general, 'bipolares' a todas aquellas oraciones en cuyo interior se da una relación de interordinación entre las cláusulas que normalmente las constituyen”. Así, pues, la bipolaridad presupone que los elementos de la construcción son complementarios, por lo que deja de haber subordinación de uno respecto del otro. No obstante, cuesta dar con una justificación sintáctica satisfactoria. Así, Gutiérrez Ordóñez afirma que en su consideración hay al menos dos cuestiones delicadas; de un lado, que "no se puede confundir relación sintáctica con una relación semántica. Las adversativas se relacionan sintácticamente con las coordinadas y semánticamente con las consecutivas y las condicionales" (Gutiérrez Ordóñez, 1978/1997: 29); de otro, que el concepto interodinación "es asimismo delicado. ¿Qué se ha de entender por interdependencia, por exigencia mutua? ¿Cómo determinar los casos de interordinación?" (Gutiérrez Ordóñez, 1978/1997: 31). Todo ello le lleva a concluir que "las bipolares no son oraciones interordinadas, sino subordinadas o coordinadas (en el caso de las adversativas)" (Gutiérrez Ordóñez, 1978/1997: 38). En el mismo sentido transita López García (1999: 3539), para quien “el problema es si tal complementariedad puede ser caracterizada como noción funcional: aparte de su definición lógica en términos de interordinación o interdependencia, la cual desborda incluso el ámbito de lenguaje, no parecen existir razones gramaticales que den cuenta de esa propiedad".

\subsection{Recapitulación}

Una clasificación consistente y exhaustiva exige fijar de manera precisa dos cuestiones: de un lado, las unidades sintácticas en las que se pueden formalizar los enunciados; de otro, los tipos de relación que pueden establecerse dentro ellas. En lo que 
se refiere a las unidades suscribiremos en lo esencial la descripción establecida en la $N G L E$. Por tanto, estableceremos una distinción, por una parte, entre sintagmas y oraciones, y, por otra, entre oraciones simples y compuestas. Si bien la consideración de los sintagmas como nominales, adjetivales o-desde otra óptica, en este caso formal- preposicionales no plantea en principio grandes problemas, no sucede lo mismo con lo referido a los distintos tipos de unidades oracionales. Por ello, se hace oportuno realizar algunas reflexiones al respecto. Este es el planteamiento de partida del texto académico:

Las oraciones simples establecen una relación predicativa, es decir, ponen en conexión un sujeto con un predicado siempre que no contengan otras oraciones que ocupen alguno de sus argumentos o modifiquen a alguno de sus componentes. (§1.131)

Se denomina oración compuesta a la que contiene una o varias subordinadas. El concepto de oración compuesta se extiende también en la mayoría de los estudios a las oraciones formadas por coordinación de otras. (§1.13ñ)

Entendemos, pues, como oración simple la que incorpora una sola predicación y por compuesta la que incluye al menos una subordinada. Hemos limitado el concepto de oración compuesta a la definición más restrictiva de las dos recogidas en la $N G L E$, aunque con una precisión, pues incluiremos no solo aquellas que incluyan oraciones subordinadas, sino también grupos verbales dependientes. El motivo es que entenderemos la coordinación no como un tipo de oración sino de relación que se puede establecer en el marco de distintas categorías sintácticas, sean oracionales o no. Un estudio de la naturaleza sintáctica del texto escrito deberá dar cuenta exclusivamente de las coordinaciones homocategoriales de predicaciones verbales con independencia de su función dentro de la unidad oracional en la que se insertan. Por tanto, limitaremos el estudio de la coordinación a los contextos de relación paratáctica en el sentido que definen esta última autores como López García (1999: 513): "Convencionalmente, se suele aplicar el término 'coordinación' tanto a la unión de frases como a la de oraciones, en tanto la 'parataxis' sólo se aplica a la unión de oraciones". Así, consideraremos la coordinación entre oraciones simples, entre oraciones compuestas, entre oraciones simples y compuestas, entre verbos auxiliados en las perífrasis, entre oraciones subordinadas y entre predicaciones verbales dentro de oraciones subordinadas.

Para la consideración e identificación de las oraciones subordinadas partiremos también de la propuesta académica, de largo recorrido en la tradición gramatical. Son subordinadas "las que dependen de alguna otra categoría a la que complementan o modifican. Estas oraciones desempeñan alguna función dentro del grupo sintáctico al que pertenecen "( $(1.131)$. Y esto con independencia de que tal grupo sintáctico sea oracional (lo que, de hecho, sucede la mayor parte de las ocasiones) o no.

No obstante, a la hora de establecer la taxonomía de oraciones subordinadas habrá que efectuar algunas precisiones en relación con la propuesta de la $N G L E$, que serán convenientemente explicadas y justificadas. Debemos considerar que el problema de fondo reside en la reconocida y reconocible inconsistencia de la descripción sintáctica tradicional, en la que se han entrecruzado hasta cuatro perspectivas diferentes de análisis. Así, se defiende (o no) la existencia de subordinadas sustantivas, adjetivas y adverbiales desde la función que la subordinada desempeña en el marco del grupo sintáctico en el que se integra; en segundo lugar, se describen las subordinadas 
de relativo tomando en consideración la naturaleza de los nexos usados; en tercer término, se distinguen subordinadas de infinitivo, gerundio o participio si se fija la atención en la naturaleza morfológica de la predicación verbal. Finalmente, se propone la existencia de causales, consecutivas, ilativas, concesivas, etc. a partir del significado que aportan.

\section{Clasificación de subordinadas}

Con el objeto de evitar al máximo paradojas categoriales propondremos una clasificación en la que atenderemos a tres variables fundamentales que se recogen de manera explícita en el texto académico: la relación sintáctica entre la oración principal y la subordinada, la estructura argumental de la oración principal y la función sintáctica de la subordinada? .

La primera distinción la estableceremos entre subordinadas insertas y periféricas considerando el grado de inclusión que exhiban en la oración principal; según esto las periféricas no cumplirían una función sintáctica dentro de la oración principal. Esta variable permite establecer una diferencia entre las construcciones condicionales, las concesivas y las ilativas respecto del resto de las subordinadas.

En segundo lugar, dentro de las insertas cabe valorar la función de las subordinadas en la estructura argumental. Recordemos que en la descripción sintáctica los complementos se clasifican como argumentos y adjuntos según aporten información necesaria o marginal a los predicados; es, pues, una distinción de naturaleza tan semántica como sintáctica. Según la $N G L E$ : "los argumentos aportan información exigida o pedida por el significado del predicado (...) Otros que aportan informaciones no exigidas por ellos (...) se llaman adjuntos" ( $\$ 1.12 f)$. Pues bien, habitualmente se establecen correspondencias entre las naturalezas argumentales y las funciones sintácticas de los complementos tanto dentro del SN como del SV. Así, por ejemplo, la NGLE nos recuerda que son complementos argumentales del SV el sujeto, el complemento directo, el complemento de régimen preposicional y, a veces, el complemento indirecto.

Distinguiremos, en primer lugar, las subordinadas sustantivas de las demás toda vez que son las que se utilizan para construir argumentos de naturaleza oracional. Tanto es así, que "las subordinadas sustantivas se denominan también argumentales porque con escasas excepciones (...) son las únicas que constituyen argumentos de algún predicado" (\$1.13o).

Desde esta variable podemos, asimismo, diferenciar las construcciones oracionales que, siendo insertas, constituyen atributos y complementos predicativos, que no son considerados ni argumentos ni adjuntos puesto que su función se acerca más a la de los predicados que a la de los complementos. Así, la $N G L E$ apunta lo siguiente:

(L)os verbos copulativos y semicopulativos no son propiamente predicados, sino que más bien introducen el verdadero elemento predicativo, esto es, el atributo. Por el contrario, los verbos plenos tienen argumentos (...); es de-

9 No obstante, en el caso de la descripción de las denominadas construcciones oracionales, (específicamente en el caso de las insertas en función de adjunto en el SV y las periféricas) se asumirá una perspectiva de naturaleza semántica. 
cir, restringen o acotan semánticamente los elementos de los que se predican. El término complemento predicativo, que procede de la tradición gramatical francesa, se creó para reflejar la idea de que esos segmentos no son los únicos predicados que intervienen en la secuencia, sino que constituyen más bien predicaciones que se agregan o se superponen a la introducida por algún verbo pleno o principal (§37.1.q)

Quedarían en tercer lugar las subordinadas en función de adjunto. Dentro de ellas cabe establecer una distinción según los complementos adjuntos lo sean del SN o del $\mathrm{SV}$. En el primer grupo incluiremos las subordinadas de relativo y las construcciones adjetivas. La NGLE confirma tal asignación: "Son adjuntos los adjetivos calificativos, las oraciones de relativo, muchos modificadores preposicionales del sustantivo o del adjetivo" (§1.12f). La no consideración como adjuntos de todos los complementos preposicionales del sustantivo, muchos de los cuales son considerados argumentales, especialmente cuando van introducidos por la preposición de, nos decide a analizar las subordinadas sustantivas con función de complemento preposicional del nombre o del adjetivo dentro de las construcciones oracionales argumentales que describimos en primer lugar ${ }^{10}$.

El segundo grupo sería el correspondiente a los adjuntos del verbo. Al valorar su naturaleza sintáctica se observa que en la $N G L E$ se las etiqueta como "oraciones subordinadas adverbiales y grupos conjuntivos" (§39.3a). Sin embargo, se reconoce más adelante que "el concepto de 'subordinada adverbial' se usa aquí en sentido amplio, puesto que en el más estricto presenta numerosas dificultades" (§39.3y). En cualquier caso, a la hora de catalogar estas construcciones en función de adjunto tomaremos como base la clasificación semántica que de tales complementos propone la $N G L E$ en los epígrafes 39.5 y siguientes. Distinguiremos, por un lado, las espaciales, temporales y modales, que son las que tradicionalmente se han asociado a la subordinación adverbial; y por otro, algunas de las consideradas subordinadas adverbiales impropias: consecutivas, causales, finales, comparativas, aditivas y exceptivas.

\subsection{Subordinadas insertas argumentales: las subordinadas sustantivas}

Según la NGLE, "se denominan tradicionalmente ORACIONES SUBORDINADAS SUSTANTIVAS (...) las que desempeñan las funciones características de los sustantivos o los grupos nominales" (§43.1a). La configuración estructural de las subordinadas sustantivas con verbo conjugado no deja lugar a dudas: una conjunción subordinante que y una oración que constituye el llamado término de la conjunción. De ello se deduce que la opción de análisis asumida por el texto académico es la que incluye el nexo dentro de la oración subordinada.

La descripción de la Academia incluye explícitamente subordinadas sustantivas de sujeto, de complemento directo y como término de preposición; en este último caso podrán funcionar como complemento del nombre, del adjetivo o del verbo.

10 Como se apunta en la $N G L E(\$ 43.5 \mathrm{~h})$, no todos los complementos preposicionales del nombre o del adjetivo son siempre de naturaleza argumental, como sucede cuando se trata de complementos de régimen dependientes de un nombre. Sin embargo, a la vista de que prácticamente todos de los identificados en nuestro corpus cumplen tal condición, se ha optado por mantener las subordinadas sustantivas con función de complemento preposicional del nombre o del adjetivo dentro de las construcciones oracionales argumentales. 
Asumiendo que en todos los casos se trata efectivamente de subordinadas sustantivas, no contemplaremos en el estudio de las subordinadas insertas argumentales aquellas subordinadas sustantivas que formen complementos preposicionales del verbo que no sean complementos de régimen. Apoyamos nuestra postura en la propia percepción de la $N G L E$, que asigna a esos grupos preposicionales función no argumental sino de adjunto.

Asimismo, incluiremos en este grupo las subordinadas sustantivas que subyacen a las llamadas interrogativas indirectas en función de complemento argumental y a las construcciones de estilo directo ${ }^{11}$. Estas no son recogidas como tales de manera explícita en la $N G L E$, así que en su inclusión asumimos la posición defendida entre otros por Gutiérrez Ordóñez (1997), quien se fija en que, aun cuando no aparece un transpositor, responden adecuadamente a las pruebas de sustantivación oracional; concluye que la nominalización es producida por la pausa ortográfica. De hecho, en la construcción de las subordinadas sustantivas de estilo directo identificadas en nuestro corpus, se observa que de forma sistemática se marcan los límites oracionales mediante signos de puntuación, si bien los utilizados no son siempre los mismos:

1. "No había visto algo así en mi vida", nos confesaba un español que reside allí desde hace treinta años.

\subsection{Subordinadas oracionales insertas en función de adjunto en el SN: subordinadas de relativo y construcciones adjetivas}

Por lo que toca a las subordinadas de relativo, la gramática académica las define con absoluta precisión: "Se denominan oraciones subordinadas de relativo (también oraciones de relativo o simplemente relativas) las encabezadas por un pronombre, adverbio o determinante relativo, o bien por los grupos sintácticos que estas voces forman" (\$44.1a). En términos taxonómicos seguiremos asimismo la posición académica, que distingue relativas con antecedente expreso y con antecedente implícito o semilibres.

Parece oportuno aportar ahora alguna reflexión acerca de la renuncia de la $N G L E$ a la consideración de las subordinadas adjetivas que no sean oraciones de relativo (§1.13o). Desarrolla la cuestión al definir las relativas especificativas: "La tradición gramatical ha denominado también a las relativas especificativas (o, al menos, a las que poseen antecedente expreso) SUBORDINADAS ADJETIVAS. No obstante, se reconoce hoy que el paralelismo funcional entre los adjetivos y las oraciones de relativo es parcial" (\$44.1n). Por el argumento expuesto, la $N G L E$ abandona la etiqueta de $s u$ bordinadas adjetivas. Apenas descubrimos una referencia a ellas, y sin nombrarlas, en el capítulo dedicado al participio:

En opinión de muchos gramáticos, también se obtienen construcciones oracionales, aunque no absolutas, cuando el participio es un modificador nominal. Entienden estos autores que las estructuras que forman los participios en dichos contextos constituyen los equivalentes no flexivos o no personales de las oraciones de

11 Cabría incluir en este grupo las exclamativas indirectas aun cuando no hemos identificado ninguna en nuestro corpus. 
relativo, por lo que se han denominado relativas reducidas. Ilustra esta construcción el segmento cerrado entre corchetes en el partido [jugado ayer brillantemente por Boca Juniors]. (...) Para otros gramáticos, no hay, en cambio, justificación suficiente para defender la naturaleza oracional del segmento que jugado encabeza, que no perdería su carácter de grupo verbal en esta oración ( $\$ 27.81$ y $§ 27.8 \mathrm{~m})$

Tal renuncia terminológica afectaría a la exhaustividad del modelo de análisis propuesto, puesto que no daríamos cuenta de las estructuras articuladas sobre la base de un participio que funcionan como modificador cuando se insertan en grupos nominales o en construcciones absolutas. Toda vez que no hay consenso a la hora de evaluar su naturaleza oracional, las designaremos como construcciones adjetivas. Para saber si construyen grupos verbales, consideramos que serán participios si van acompañados de complementos predicativos, si admiten adverbios de modo o si no permiten la anteposición al sustantivo que acompañan. Además, asumiremos que se trata de un participio y no de un adjetivo si va acompañado de algún complemento de los que normalmente irían ligados a un verbo conjugado.

\subsection{Construcciones oracionales insertas en función de adjunto en el SV: temporales, locativas y modales}

Debemos detenernos a continuación en las oraciones que tradicionalmente se han denominado subordinadas adverbiales propias: su inclusión en el análisis necesita una justificación mayor toda vez que la $N G L E$ no acaba de explicitar inequívocamente si existen o no subordinadas de esta naturaleza. Sin referirse a ellas de forma expresa, parece que las asocia a las construcciones que tradicionalmente se han denominado adverbiales propias, hasta el punto de que estas las ilustra con un ejemplo de construcción modal: "Este autor escribe como a mí me gustaría escribir" (§1.13n).

También se usan como ejemplo locativas y modales cuando se nos recuerdan los problemas referidos al concepto mismo de subordinación adverbial y se afirma que:

[La subordinación adverbial] constituye un tipo sintáctico que se cruza o se traslapa con otras clasificaciones oracionales. En efecto, las oraciones de relativo contienen pronombres o adverbios relativos, como se ha explicado. La presencia del adverbio relativo donde en El libro está donde te dije lleva a analizar la oración subrayada como un tipo de subordinada relativa (22.8), concretamente una relativa sin antecedente expreso (...). A la vez, esta oración puede sustituirse por un adverbio (allí), por lo que constituye una subordinada adverbial. El mismo problema se plantea en el ejemplo, ya introducido, Este autor escribe como a mi me gustaría escribir. La presencia del adverbio relativo como asimila el segmento subrayado a las relativas sin antecedente expreso (...), pero la oración admite sustitutos adverbiales y constituye un complemento circunstancial de modo o manera, por lo que se considera tradicionalmente una oración subordinada adverbial $((\S 1.13 \mathrm{q}$ y siguientes).

De lo dicho se podría inferir que no cabe hablar de oraciones temporales, modales o de lugar en aquellos casos (muy frecuentes, por otra parte) en los que las construcciones están encabezadas por adverbios relativos como donde, cuando o como. Sería suficiente con incluirlas en el estudio de las oraciones de relativo. Asumamos la hi- 
pótesis. Nos quedaría responder a dos cuestiones: primero, ¿cómo hemos de valorar el resto de construcciones con idéntico de valor circunstancial y que utilizan nexos que no son adverbios relativos? Después, ¿cómo hemos de considerar las construcciones de este mismo valor circunstancial en las que se usan formas no personales del verbo? Son, como es bien sabido, cuestiones largamente debatidas en el tiempo y a la espera de una propuesta aceptada por la mayoría.

A partir de esta heterogeneidad descriptiva, ¿qué hacemos con este grupo de construcciones? Debemos optar por alguna de las rutas ya marcadas en la descripción sintáctica. Y parece que lo más lógico sería asumir una de orientación semántica, en tanto que es la misma que se ha propuesto habitualmente para describir el resto de las construcciones que tradicionalmente se habían incluido en el grupo de las subordinadas adverbiales y que también se utiliza a la hora de clasificar los complementos adjuntos. Esta es la percepción que parece que subyace al trabajo de García Fernández (1999: 3176), dedicado a las oraciones subordinadas temporales:

Estas oraciones establecen una relación temporal entre el evento de la oración principal y el evento de la oración subordinada. La relación temporal entre ambas oraciones depende del significado del conector temporal que introduce la oración subordinada.

Como puede verse, la naturaleza semántica de la relación establecida entre subordinada y principal se convierte en el argumento descriptivo primario. El mismo que usa la $N G L E$ cuando define las construcciones causales:

La oración subrayada en Se quedaron en casa porque hacía demasiado calor constituye una oración subordinada CAUSAL. Se introduce en ella la CAUSA cuyo EFECTO expresa la oración principal. (\$46.1a)

La asunción de este punto de vista nos permitiría superar una paradoja como es la que se observa al comparar oraciones construidas con los adverbios relativos donde, cuando y como con o sin antecedente expreso. Desde la definición aportada por García Fernández cabría dudar si las que tienen antecedente expreso serían auténticas construcciones temporales puesto que no es posible establecer esa relación temporal entre las acciones indicadas en la oración principal y la subordinada en términos de anterioridad, posterioridad, simultaneidad, etc. Nuestro corpus muestra tres ejemplos en los que se usa cuando con antecedente expreso (todas explicativas):

2. La última fue hace aproximadamente un año, cuando varios clientes se quejaron de haber encontrado hormigas en su comida.

En cambio, hemos detectado 27 construcciones sin antecedente expreso, todas ellas con sentido especificativo y con ese valor temporal que se indica en la definición de García Fernández:

3. Cuando los padres y el hermano menor de la detenida comieron el flan que había de postre, empezaron a sufrir convulsiones y a ponerse lívidos.

Asimismo, la conmutación de la subordinada por un adverbio de tiempo es posible en el ejemplo 3. Sin embargo, no lo es, al menos de forma evidente, en 2. En otras 
palabras, 3 sería una oración (adverbial) temporal de relativo, razón por la que estaría justificado integrar su estudio tanto en un grupo como en el otro. Sin embargo, no sucedería lo mismo con 2.

A partir de este hecho, incluiremos dentro de las subordinadas de relativo con función de adjunto en el SN a las que incorporan el adverbio relativo con antecedente expreso, y en el grupo de construcciones (adverbiales) temporales con función de adjunto en el SV a las restantes. La posición asumida aparece implícitamente reconocida en la $N G L E$ cuando, al analizar la sintaxis de los tiempos y las partículas temporales, asume la existencia de subordinadas de significación temporal encabezadas por cuando:

Constituyen una excepción las subordinadas de significación temporal introducidas por cuando y mientras, y también las oraciones que se subordinan a los adverbios antes y después, que se asimilan en gran parte a las anteriores. Así, el tiempo que se elija para el verbo llegar en el esquema Arturo escribió la carta \{cuando-mientras-antes de que-después de que) Clara LLEGAR estará en función del pretérito escribió. (\$24.9b)

Nuestra posición, que privilegia la función de la subordinada en la principal por encima de la naturaleza morfológica del nexo, permite superar además otra considerable fuente de problemas, como es la heterogeneidad de las partículas temporales que pueden funcionar como funtivos en este tipo de construcciones. Efectivamente, como, cuando y donde son adverbios de relativo que permitirían incluir las construcciones en el estudio de las relativas, ¿pero qué hacer con las restantes?

La heterogeneidad de su naturaleza tiene como efecto que su clasificación sea muy controvertida y compleja, y esa dificultad se plasma en la redacción del texto académico. Así, es ilustrativo el caso de antes de que y después de que, que aparecen sucesivamente clasificadas como conjunciones subordinantes y locuciones conjuntivas, para al final concluir que es problemático considerarlas locuciones conjuntivas porque admiten cuantificadores. Las dificultades afectan a otras muchas partículas. Así, se afirma que mientras posee propiedades en común con las conjunciones subordinantes y con los adverbios de relativo, y posteriormente se indica sin más que es una conjunción. Asimismo, en cuanto aparece clasificado como adverbio de relativo, mientras que enseguida que lo es como locución conjuntiva, aunque se reconoce que no hay unanimidad al respecto entre los investigadores.

Solo son algunos ejemplos para ilustrar la enorme complejidad de la cuestión. No es el propósito de este trabajo abordarla, ni mucho menos; para los objetivos del mismo nos basta con reconocer lo evidente, como es su condición de nexos o partículas que ponen en relación la oración subordinada con la principal (tengan o no función sintáctica dentro de la subordinada, como sucede en el caso de las relativas). Dicho de otro modo, a nuestra investigación le interesa no tanto cuál es la naturaleza y el comportamiento sintáctico de tales nexos, sino cuáles son los que efectivamente se usan en la construcción de oraciones, en este caso temporales.

Por todo lo dicho, consideraremos como construcciones temporales, espaciales y modales aquellas asentadas en una forma personal o no personal del verbo que aporten contenidos de esa índole y que funcionen como complementos adjunto de una oración. Todo ello con independencia de su estructura sintáctica, que en unos casos responderá a la de una subordinada de relativo y en otros a una subordinada sustantiva. 
Tal percepción se acerca a la asumida por la $N G L E$ cuando denomina subordinadas adverbiales a las modales de gerundio. De hecho, la consideración de las subordinadas de gerundio es ciertamente espinosa, pues parece que en la gramática académica solo se reconoce como tales a aquellas en las que este construye un adjunto circunstancial que expresa el modo de realización de una acción, mientras que quedarían fuera de ellas los grupos verbales en los que el gerundio funciona como complemento predicativo que expresa la situación o el estado de aquello a lo que predican. Con el problema añadido de que los límites entre el adjunto y el predicativo son con frecuencia borrosos, como reconoce el texto académico ( $\$ 27.1 \mathrm{p} \mathrm{y} \$ 27.6 \mathrm{c})$, en el que se nos recuerda que para algunos se trata de una distinción semántica difícilmente aplicable porque la sintaxis carece de recursos formales para objetivarla.

Esta posición no es ni mucho menos compartida por todos los investigadores. Así, por ejemplo, Fernández Lagunilla (1999) defiende que el gerundio origina dos tipos de construcciones según modifiquen a la oración completa o solo al verbo. En el primer caso, se trataría de gerundios en construcciones con significación semántica concesiva, condicional, causal, consecutiva... y solo en ellas tendrían naturaleza oracional. Eso deja fuera de tal consideración tanto a los gerundios adjuntos como a los predicativos; y no solo a estos últimos, como sucedía en el texto académico. En todo caso, la posición nos despierta algunas dudas que derivan de atribuir categoría de oración a una construcción según la naturaleza oracional o verbal de la unidad sobre la que inciden. Sin embargo, nos parece mucho más interesante su otra aportación en ese mismo trabajo cuando afirma que estos dos tipos de gerundio tienen en común que se trata de elementos subordinados, que no pueden aparecer solos como oraciones independientes excepto en contextos muy especiales. Para ella, el gerundio en todos estos casos es un verbo, y esa naturaleza se demuestra merced a determinadas pruebas morfológicas y sintácticas como, entre otras, que pueden llevar complementos y modificadores o que pueden tener sujeto propio. Si es así, reconoceremos la existencia de construcciones con el verbo en forma de gerundio con valor de adjunto circunstancial, que podrá serlo temporal, modal, causal, etc. y que analizaremos dentro de las construcciones correspondientes a cada una de esas naturalezas semánticas. Sin embargo, renunciaremos a establecer grupos de construcciones subordinadas sobre la base de la naturaleza morfológica de la predicación verbal. Así, no incluiremos en nuestra taxonomía un grupo como tal de oraciones subordinadas de gerundio, como tampoco lo habrá de oraciones de infinitivo o de participio.

\subsection{Construcciones oracionales insertas en función de adjunto en el SV: consecutivas, causales, finales y comparativas.}

La consideración de estas construcciones en la tradición gramatical es ciertamente polémica y refleja posiciones y enfoques muy diversos. Pongamos solo un ejemplo: en 1999 se publica la Gramática Descriptiva de la Lengua Española, coordinada por Ignacio Bosque y Violenta Demonte, y editada al amparo de la Real Academia Española. Es sin ningún género de dudas una obra clave cuya calidad y agudeza está fuera de toda duda. Pues bien, es ilustrativo repasar la percepción que de la cuestión traslucen los diferentes trabajos referidos a estas construcciones. En casi todos ellos parece que se parte de una orientación semántica en el momento de categorizarlas. Sin embargo, esta ofrece diferencias importantes; así, Galán (1999) denomina su- 
bordinadas a las causales y las finales aun cuando su trabajo se asienta en definir el "ámbito semántico de la causalidad" y en proponer una tipología semántica de causales y finales. Por su parte, Montolío (1999) prefiere hablar de construcciones condicionales, dentro de las que incluye "un nutrido conjunto de estructuras sintácticas notablemente diferentes entre sí". En su estudio propone un análisis que ha de ser simultáneamente gramatical, lógico, cognitivo, semántico y pragmático. Esa diversidad también aparece en Álvarez (1999) al evaluar las construcciones consecutivas: son un "conjunto heterogéneo tanto desde el punto de vista de su sintaxis como de su significado". Distingue dos tipos de consecutivas, subordinadas y coordinadas, las últimas de las cuales coinciden con las que en otros estudios sintácticos denominan construcciones ilativas. El mismo punto de partida semántico es el que orienta el estudio que Flamenco (1999) hace de las construcciones concesivas y las adversativas al afirmar que se trata de dominios nocionales muy próximos. Su valoración sintáctica es, sin embargo, distinta: concesivas y adversativas están en la frontera entre lo oracional y lo discursivo, y las ubica en el entorno de las bipolares o interordinadas, que es además una unidad cuya naturaleza sintáctica es puesta en tela de juicio por López García (1999) en el capítulo dedicado a la hipotaxis y la parataxis dentro de la misma obra colectiva; en cualquier caso, termina por afirmar que las adversativas están más cerca de las coordinadas y las concesivas, de las subordinadas. Frente a todos ellos, Pérez Saldanya (1999) agrupa causales, consecutivas, concesivas, condicionales, finales, temporales, locativas y modales bajo la denominación común de subordinadas adverbiales.

Los cambios en la valoración de estas construcciones son constantes en los seis capítulos citados de uno de los trabajos más importantes de la gramática descriptiva de nuestra lengua. El objetivo planteado por los directores del trabajo de conseguir un "marco conceptual de conciliación" no se alcanza, puesto que los puntos de partida que alumbran a todos esos excelentes investigadores que hemos citado son enormemente diversos en relación con los mecanismos sintácticos de nuestra lengua: la descripción supone una interpretación de los mismos. La formulación de este hecho por parte de Bosque y Demonte (1999: XIX) en la introducción de su Gramática es impecable:

La gramática es la disciplina que estudia sistemáticamente las clases de palabras, las combinaciones posibles entre ellas y las relaciones entre esas expresiones y los significados que puedan atribuírseles. Esas propiedades, combinaciones y relaciones pueden formularse de maneras diversas y puede haber, por lo tanto, muchas gramáticas de la Gramática de una lengua.

La cuestión es que en ese trabajo de descripción de las construcciones que ahora nos ocupan, la sistematicidad se resiente porque conviven varias gramáticas dentro de una misma gramática.

Así pues, en lo que toca a nuestro objetivo de aportar una taxonomía consistente estaríamos ante un callejón sin salida del que tal vez nos pueda sacar la NGLE. Recordemos que el texto académico no considera de manera inequívoca la existencia de subordinadas adverbiales, por lo que se usa tal etiqueta de forma muy restringida: "Cuando se desee recordar su contenido tradicional o se desee abarcar por entero el grupo que corresponde a esas oraciones en la tradición gramatical hispana. También se aplicará el término subordinada adverbial a las oraciones subordinadas de gerun- 
dio" ( $\$ 1.3 u)$. A cambio, se prefiere hablar de construcciones. Tal consideración es de naturaleza esencialmente semántica y persigue, al final, establecer algún tipo de diferencia entre unidades que, entendidas formalmente, resulta difícil o injustificado analizar separadamente. En el capítulo 43, la $N G L E$ apunta que su estructura sintáctica es la propia de los grupos preposicionales con función de adjunto. Por ello, en términos estrictamente sintácticos se debería hablar de oraciones subordinadas sustantivas con función de término de preposición:

El grupo preposicional formado mediante la pauta "preposición + subordinada sustantiva" ejerce también la función de adjunto, como en el caso de para (Trabaja para que coman sus hijos) o sin (Estudia sin descansar). (\$43.5e)

Varios verbos de movimiento (ir, venir, subir, correr) y algunos que no lo son propiamente, como quedarse, admiten subordinadas sustantivas en complemento preposicional con $a$ de sentido final (a menudo en alternancia con para). ( $\$ 43.5 \mathrm{~g}$ ) En el primero de los ejemplos, sintácticamente se trataría de una subordinada sustantiva, pero semánticamente es una construcción final. Sin embargo, al texto le cuesta renunciar a etiquetarlas como subordinadas:

Se usarán asimismo en el sentido lato los términos SUBORDINADA CAUSAL y SUBORDINADA FINAL, que cuentan con cierta tradición en la lingüística hispánica, junto a los también laxos CONSTRUCCIÓN CAUSAL y CONSTRUCCIÓN FINAL. (§46.1b)

En cualquier caso, nuestro objetivo no es profundizar en la estricta naturaleza sintáctica de estos grupos, sino más bien en cuáles son las preferencias en la construcción de los textos, entendidas estas desde una perspectiva discursiva. Desde esa posición, nos resulta mucho más útil contar con una taxonomía que nos permita matizar con mayor precisión la naturaleza de las elecciones expresivas. Por ello, optaremos por distinguir estas construcciones de las subordinadas sustantivas. La razón es sencilla: si, al final, la mayor parte de construcciones sintácticas solo se puede adscribir a un grupo, nuestras opciones a la hora de establecer las diferencias de uso quedarían mucho más limitadas. De este modo, será mucho más rico el análisis.

Según el texto académico son construcciones consecutivas las construidas a partir de un determinante cuantificativo o cualificativo:

Se llaman CONSECUTIVAS PONDERATIVAS (o simplemente CONSECUTIVAS) las construcciones formadas por los determinantes tanta/tantos/tantas (o su variante apocopada tan), así como tal/tales cuando aparecen seguidos de una oración subordinada encabezada por la conjunción que. $(\$ 45.14 \mathrm{a})$

Así, pues, se configuran a partir de una subordinada encabezada por el nexo QUE. Es llamativo que en ningún momento se compromete con la naturaleza de tal subordinada ni la del nexo: "Se ha debatido numerosas veces la cuestión de si deben analizarse como relativas o como consecutivas las oraciones subordinadas a las que se alude en el apartado precedente" (\$45.141).

La NGLE presenta de manera asociada las construcciones causales, finales $e$ ilativas; aun sin definirlas explícitamente en términos formales, parece reconocer su naturaleza subordinada; sin embargo, las define desde su naturaleza semánti- 
$\mathrm{ca}^{12}$. Así, afirma lo siguiente en lo relativo a cada uno de los tres grupos (obsérvese que el texto académico utiliza como sinónimos los términos construcción y oración subordinada):

La oración subrayada en Se quedaron en casa porque hacía demasiado calor constituye una oración subordinada CAUSAL. Se introduce en ella la CAUSA cuyo EFECTO expresa la oración principal. (...) Las construcciones FINALES más características expresan el propósito de las acciones o los sucesos, noción que no está desvinculada del concepto de causa. (...) Las construcciones ILATIVAS, por último, presentan ciertas informaciones como consecuencias lógicas o naturales de otras aseveraciones de las que se derivan. (§46.1a)

En cambio, no hay referencia específica en la NGLE a construcciones comparativas, sino que las incluye en el marco general de la comparación. No obstante, se reconoce que las comparaciones se pueden realizar mediante procedimientos léxicos verbales, adjetivales o de otro tipo ( $\$ 45.1 b)$. Sin embargo, considera que muchas de las llamadas oraciones comparativas realmente no son sino oraciones simples que integran una construcción comparativa no oracional. Siendo cierta tal afirmación, no deja tampoco de serlo que se pueden identificar oraciones comparativas como las siguientes:

4. Por eso, debemos inculcar a los más pequeños unos hábitos saludables si queremos que sean tan felices como lo fuimos nosotros.

Por ello, en el análisis interpretaremos como construcciones comparativas aquellas en las que las nociones comparadas se expresan de mediante un grupo verbal en el segundo término de la comparación.

\subsection{Construcciones oracionales insertas en función de adjunto en el SV: aditivas y exceptivas.}

El estudio de corpus que hemos realizado nos ha descubierto una serie de construcciones que tienen difícil cabida en las taxonomías habituales y que, sin embargo, se acercan formalmente a las que tradicionalmente se han denominado subordinadas adverbiales. Se trata de aquellas que tienen un valor semánticamente aditivo o contraargumentativo y que, sin embargo, no son construcciones coordinadas en tanto que no van ligadas por una conjunción coordinante propiamente dicha y que se observa, además, una diferencia de rango sintáctico entre las unidades relacionadas. Son casos como los siguientes:

5. Los primeros declaran que, además de ser una opción económica, elimina la desigualdad y la discriminación;

6. ¿No sería más razonable tratar de resolverlos en vez de erradicarlos?

7. Un niño obeso, aparte de que no suele ser bien aceptado, habitualmente sufre acoso escolar.

\footnotetext{
12 Pese a establecer vínculos de naturaleza semántica con las causales y finales, hemos preferido excluir las ilativas de este capítulo toda vez que no está claro que desempeñen función de adjunto en el SV.
} 
Hernanz (1999: 2332) expone que "particularmente controvertida resulta la concreción del estatuto sintáctico de tales construcciones, consideradas coordinadas por algunos autores y subordinadas por otros". La autora propone que, si las analizamos como subordinadas, por exclusión han de ser incluidas en el ámbito, que reconoce heterogéneo, de las adverbiales. Describe distintos argumentos a favor y en contra de adscribirlas a uno de los grupos para terminar incluyéndolas entre las bipolares. Por su parte, la NGLE describe estas construcciones como complementos preposicionales compuestos por un adverbio o una locución adverbial y una preposición combinada con una oración subordinada sustantiva de infinitivo o de verbo finito que funciona de término de preposición $(\$ 26.11$.s y $\$ 30.12 \mathrm{~m})$. Volvemos a un espacio de límites sintácticamente borrosos, por lo que recuperaremos el criterio semántico aplicado a determinados tipos de subordinadas sustantivas y las llamaremos construcciones aditivas y exceptivas. En ese sentido, seguimos a Porto Dapena (1993: 43), para quien son complementos que indican suma, resta o concesión.

\subsection{Construcciones insertas con función no argumental ni de adjunto: atributivas y predicativas}

Entendemos que nuestro análisis tiene que valorar un grupo de construcciones ciertamente difíciles de categorizar y que se corresponde con la construcción de complementos predicativos de ciertos verbos de percepción o de atributos en el caso de oraciones copulativas y semicopulativas. Nos referimos a aquellos casos en que estos complementos construyen grupos verbales en torno normalmente, aunque no exclusivamente, a un infinitivo, un gerundio o un participio. En el corpus hemos identificado casos como los siguientes. Fijamos nuestra atención en las partes en cursiva de los ejemplos:

8. Algunos padres no quieren que sus hijos vayan vestidos exactamente de la misma manera que otros centenares de alumnos, mientras que otros prefieren que sea así para que haya igualdad entre todos.

9. "El ventrículo izquierdo quedó absolutamente deformado, afirma José Antonio Pérez, jefe de cardiología del Hospital 12 de octubre de Madrid.

En la $N G L E$ estos grupos verbales son considerados como oraciones subordinadas cuando se construyen con un nexo y un verbo conjugado. Así sucedería en ejemplos como este, que está tomado de la gramática académica:

10. La vi que iba a la cocina a buscar una botella.

La discusión teórica se plantea sobre si serían subordinadas sustantivas o de relativo, pues existirían argumentos en una y otra dirección. En cambio, cuando son grupos verbales construidos sobre la base de un infinitivo, un gerundio o un participio, la $N G L E$ los considera no oracionales:

11. Me lo imagino paseando por la calle.

12. Encontró a su hija acostada en la cama.

13. Le vio alejarse por la carretera. 
La discusión acerca de si estos grupos verbales son o no oracionales no está, ni mucho menos, cerrada. De hecho, la NGLE acepta que se trate de oraciones cuando se trata de un participio en función de predicativo, pero niega tal cualidad cuando se trata de infinitivos ( $\$ 26.2 \mathrm{e}$ ) y afirma que generan "otras construcciones dependientes no oracionales", si bien reconoce que es "la construcción más polémica". Por otra parte, no se compromete con una u otra interpretación en el caso de los gerundios predicativos. Todo lo más que se afirma es que "no se asimilan sintáctica ni semánticamente los predicativos de infinitivo y los de gerundio" (\$27.6.i)

No obstante, toda vez que sí hay consenso a la hora de aceptar la naturaleza verbal de tales formas no personales, las clasificaremos en nuestra taxonomía como construcciones atributivas o predicativas, según su función. Su naturaleza sintáctica es compleja y polémica: la $N G L E$ dedica el capítulo 37.4 a las oraciones y los grupos verbales en función de atributo y de complemento predicativo. Nótese que el texto académico destaca la dificultad de desentrañar la verdadera naturaleza sintáctica de tales estructuras. Así, por ejemplo, sucede con los atributos oracionales encabezados por que: en unos casos se interpretan como relativas atributivas, en otros se asocian a las consecutivas y en otros a las subordinadas sustantivas.

\subsection{Construcciones oracionales periféricas: condicionales y concesivas}

Como bien apunta la $N G L E$ "el vínculo sintáctico entre las oraciones en el periodo condicional y concesivo está en el límite mismo de las unidades que la sintaxis oracional puede considerar como propias" (§47.1.k), por lo que hay autores que no consideran que sea analizable desde las herramientas de la gramática oracional. Según la NGLE, las construcciones condicionales y concesivas quebrantarían la condición propia de las subordinadas, esto es, que cumplen una función dentro del grupo sintáctico al que pertenecen:

Los periodos condicionales y concesivos contienen subordinadas que no están INSERTAS O INCLUIDAS en las principales. Así, la prótasis de una condicional no está incluida en la apódosis, mientras que una subordinada sustantiva lo está en la oración principal y constituye por tanto un segmento de ella. Existen, no obstante, algunas excepciones a esta generalización (...) Entre los componentes de los períodos concesivo y condicional se establece una relación, de INTERDEPENDENCIA, en el sentido de que ninguno de los miembros puede ser suprimido sin alterar el significado del conjunto o incluso comprometer la gramaticalidad de la construcción. $(\S 47.1 \mathrm{~g})$

Esa relación de interdependencia que propone el texto académico, y que asumimos, nos invita a decantarnos por no considerarlas como complementos adjuntos de la oración principal.

Por otro lado, tal naturaleza se plantea desde una posición semántica, puesto que en ambos casos se reconoce y manifiesta su naturaleza subordinada, lo que sitúa la propuesta académica en la línea marcada, como veíamos más arriba, por Gutiérrez Ordóñez (1978/1997) o López García (1999). Renuncia, pues, el texto académico a considerar la opción de interpretarlas como interordinadas, entre otras cosas por la reconocida dificultad de justificar su existencia en términos sintácticos, tal y como ya apuntamos antes. 
Por ello, asumiendo que tienen características sintácticas propias, aun cuando estas no han sido descritas de forma plenamente satisfactoria desde argumentos estrictamente sintácticos, a efectos de nuestra investigación incluiremos el estudio de construcciones condicionales y concesivas en las construcciones oracionales periféricas.

\subsection{Construcciones oracionales periféricas: ilativas}

Dentro de las periféricas cabe incluir también las construcciones ilativas. Recordemos que no son pocos los investigadores que defienden que serían un modo especial de coordinación consecutiva (por ejemplo, Álvarez, 1999) o incluso una forma de interordinación (Castellá, 2001) ${ }^{13}$. Según la $N G L E$, las ilativas estarían:

“(E)n un plano más elevado de la trabazón discursiva que el que corresponde a las finales o a las causales, en cuanto que los elementos sobre los que inciden pueden caracterizarse por mayor amplitud y complejidad sintáctica. Esta propiedad las sitúa, además, en opinión de muchos críticos, entre las unidades características de la gramática del discurso o del texto. $(\$ 46.11 \mathrm{~h})$

Proponemos ubicar las construcciones ilativas en un grupo independiente aun cuando en el capítulo 46 de la $N G L E$ se las estudia junto a las causales y las finales por argumentos de naturaleza semántica. Nótese, sin embargo, que tienen una naturaleza gramatical muy diferente de las causales, consecutivas y finales aun cuando compartan con ellas el hecho de establecer relaciones de causa-efecto. En efecto, se reconoce respecto de las ilativas que:

Es muy diferente la naturaleza gramatical de otras oraciones que aluden igualmente a la consecuencia de alguna situación descrita, pero de forma que esta se presenta, en un período sintáctico diferente, como derivación natural de lo que el hablante ha expresado con anterioridad. (§46.11a)

\section{Conclusión}

El repaso a los estudios realizados desde Hunt y referidos a la madurez y la complejidad semántica ha querido servir de punto de partida para descubrir sus grandes aciertos y algunas de sus limitaciones, que son en las que inevitablemente hemos debido detenernos. La primera es de fondo, pues no es sencillo asociar complejidad y madurez sintáctica; de hecho, como hemos observado, no es tan evidente la validez de los índices de complejidad. La segunda es de forma: las páginas de este estudio se han centrado en ella y hemos querido aportar respuestas referidas a dos cuestiones que han de condicionar cualquier estudio dedicado a analizar las características sintácticas del discurso escrito: de un lado, qué tipo de unidades se han de estudiar; de otro qué procedimiento debemos aplicar.

13 La gramática académica nos recuerda en $\$ 46.11 \mathrm{~d}, \mathrm{e}, \mathrm{f}, \mathrm{g}$ que es un tipo de oración que establece relaciones formales con las causales explicativas, pero también con las coordinadas. En cualquier caso, son solo coincidencias parciales que no permiten incluirlas al lado de unas u otras. 
En lo referido a la primera cuestión, nos ha parecido fundamental establecer como unidad de estudio el enunciado en tanto que unidad mínima de comunicación y, por tanto, entendida desde un perspectiva múltiple que abarca simultáneamente consideraciones pragmáticas, sintácticas, semánticas e informativas; esto es, considerado como una unidad discursiva: es una realización comunicativa contextualizada que tiene su correlato formal en unidades sintácticas, que podrán ser oraciones o unidades menores de naturaleza sintagmática.

En lo relativo a la segunda se hace necesario establecer una clasificación coherente desde un punto de vista categorial de tales unidades. No se plantean grandes problemas en lo que se refiere a las unidades sintagmáticas, más allá del cambio de perspectiva que supone considerar sintagmas nominales y adjetivales, por un lado, y preposicionales, por otro. Sin embargo, sí son mucho mayores en lo relativo a los tipos de oraciones. Las dificultades nos han llevado a distinguir exclusivamente entre oraciones compuestas o simples según incorporen o no oraciones subordinadas o grupos verbales dependientes. En este sentido, recordemos que el texto académico solo asume de manera indiscutida la existencia de dos tipos de subordinadas: sustantivas y de relativo. Nótese que el criterio que conduce a la consideración de unas y otras es distinto: funcional en el caso de las primeras y formal (en relación con la naturaleza de los nexos) en el de las segundas. En cualquier caso, hemos usado el término subordinadas para designar a aquellas que lo sean de cualquiera de estas dos naturalezas. Sin embargo, usaremos la etiqueta construcción de la misma manera deliberadamente vaga que lo hace la NGLE. ( $(1.13 \mathrm{u})$, lo que nos permite no entrar a valorar si se trata o no de subordinadas con personalidad sintáctica propia. Por lo demás, también incluiremos en ellas las que se construyen sobre la base de una forma verbal en infinitivo y cuya naturaleza oracional es motivo de controversia.

La taxonomía propuesta se resume de la siguiente manera:

1. Unidades no oracionales

1.1. Sintagmas nominales

1.2. Sintagmas adjetivales

1.3. Sintagmas preposicionales

2. Unidades oracionales simples

3. Unidades oracionales compuestas

3.1. Construcciones oracionales insertas

3.1.1. Con función argumental:

3.1.1.1. Subordinadas sustantivas

3.1.2. Con función de adjunto

3.1.2.1. Adjunto en el SN:

3.1.2.1.1. Subordinadas de relativo

3.1.2.1.2. Construcciones adjetivas

3.1.2.2. Adjunto en el SV:

3.1.2.2.1. Construcciones de lugar

3.1.2.2.2. Construcciones modales

3.1.2.2.3. Construcciones espaciales

3.1.2.2.4. Construcciones causales

3.1.2.2.5. Construcciones finales

3.1.2.2.6. Construcciones consecutivas

3.1.2.2.7. Construcciones comparativas

3.1.2.2.8. Construcciones aditivas o exceptivas 
3.1.3. Con función no argumental ni de adjunto:

3.1.3.1. Construcciones atributivas y predicativas

3.2. Construcciones oracionales periféricas:

3.2.1. Construcciones condicionales

3.2.2. Construcciones concesivas

3.2.3. Construcciones ilativas

Nuestro empeño futuro será establecer cuál es el rendimiento de las diferentes unidades propuestas y la naturaleza cuantitativa y cualitativa del mismo en el corpus que nos ha servido como punto de partida y del que dimos cuenta en la introducción de este trabajo. A ese esfuerzo llevamos dedicando una considerable cantidad de tiempo con el objeto de ofrecer los resultadas de esta apasionante investigación. Investigación que no sería posible sin las herramientas que hemos querido fijar en estas páginas. Dejamos a juicio del lector si hemos tenido éxito o hemos fracasado en este objetivo.

\section{Obras citadas}

Álvarez Menéndez, Alfredo, "Las construcciones consecutivas", en Ignacio Bosque y Violeta Demonte (coords.), Gramática descriptiva de la lengua española, III. Madrid, Espasa Calpe, 1999, pp. 3739-3804.

Badía i Margarit, Antoni, Gramàtica de la llengua catalana. Descriptiva, normativa, diatòpica, diastràtic, Barcelona, Ediciones Proa, 1994.

Baers, Scott y William Nagy, "Syntactic complexity as a predictor of adolescent writing quality: Which measures? Which genre?", Reading and Writing, 22/2 (2009), pp. 185-200.

Bajtin, Mijail, Esthétique de la création verbale, Paris, Gallimard, 1979. Citamos por la versión en español: Estética de la creación verbal, México DF, Siglo XXI, 1982.

Bartolomé Rodríguez, Rocío, “Aplicación de los índices de madurez sintáctica al aprendizaje de la segunda lengua", en Agustín Barrientos Clavero y otros (coords.), El profesor de español LE-L2: Actas del XIX Congreso Internacional de la Asociación para la Enseñanza del Español como Lengua Extranjera (ASELE) I, Cáceres, Asele y Unv. de Extremadura, 2009, pp. 277-290

Berko, Jean y Nan Bernstein, Psycholinguistics, Fort Worth, Harcourt Brace College, 1998. Citamos por la versión en español: Psicolingüística, Madrid, McGraw-Hill, 2001.

Berman, Ruth e Irit Katzenberger, "Form and function in introducing narrative and expository texts: A developmental perspective", Discourse Processes, 38/1(2004), pp. 57-94.

Berman, Ruth y Bracha Nir-sagiv, "Clause-packaging in narratives: a crosslinguistic developmental study", en J. Guo y otros (eds.), Crosslinguistic Approaches to the Psychology of Language: Research in the Tradition of Dan I. Slobin, Mahwah NJ, Lawrence Erlbaum, 2009, pp. 149-162.

Bosque Muñoz, Ignacio y Violeta Demonte Barreto (coords.), Gramática descriptiva de la lengua española, Madrid, Espasa Calpe, 1999.

Bustos Gisbert, José Manuel, Arquitextura, Salamanca, Ediciones Universidad de Salamanca, 2013a.

- "Grado de evidenciación de la conexión textual en escritos de naturaleza expositiva", Verba, 40 (2013b), pp. 93-138.

Castellá i Lidon, Josep Mª , La complexitat lingüística en el discurso oral y escrit, Barcelona, Universitat Pompeu Fabra, 2001. Tesis doctoral. 
Crespo Allende, Nina Ma , Pedro Alfaro Faccio y Begoña Góngora Costa, "La medición de la sintaxis: evolución de un concepto", Onomazein, 24 (2011), pp. 155-172.

Cuenca Ordinyana, $\mathrm{M}^{\mathrm{a}}$ Josep, Les oracions adversatives, Valencia/Barcelona, Institut Universitari de Filologia Catalana/Publicacions de l'Abadia de Montserrat, 1991.

De Beaugrande, Robert, Text production, Norwood NJ, Ablex Publishing Corporation, 1984.

Fernández Lagunilla, Marina, "Las construcciones de gerundio", en Ignacio Bosque y Violeta Demonte (coords.), Gramática descriptiva de la lengua española, II, Madrid, Espasa Calpe, 1999, pp. 3443-3503.

Ferrreiro, Emilia, "Los límites del discurso: puntuación y organización textual", en Emilia Ferreiro y otros (eds.): Caperucita Roja aprende a escribir, Madrid, Gedisa, 1996, pp. 129-161.

Figueras Coronilla, Carolina, "La semántica procedimental de la puntuación”, Especulo, 12 (1999): www.ucm.es/info/especulo/numero12/puntuac.html. Última consulta: 12/11/2011.

-, Pragmática de la puntuación, Barcelona, Octaedro, 2001.

Fuentes Rodríguez, Catalina, "Los límites del enunciado", Estudios de Lingüistica del español, 35/1 (2014), pp. 137-160.

Galán Rodríguez, Carmen, "La subordinación causal y final”, en Ignacio Bosque y Violeta Demonte (coords.): Gramática descriptiva de la lengua española, III, Madrid, Espasa Calpe, 1999, pp. 3597-3642.

García Fernández, Luis, “Los complementos adverbiales temporales: la subordinación temporal”, en Ignacio Bosque y Violeta Demonte (coords.), Gramática descriptiva de la lengua española, II, Madrid, Espasa Calpe, 1999, pp. 3129-3208.

Gutiérrez Ordóñez, Salvador, “¿Es necesario el concepto de oración?”, en La oración y sus funciones, Madrid, Arco Libros, 1997, pp. 40-65. Publicado originalmente en Revista Española de Lingüística, 14 (1984), pp. 23-38.

—, "A propósito de cláusulas y oraciones", en La oración y sus funciones, Madrid, Arco Libros, 1997, pp. 23-39. Publicado originalmente en Archivum, 27-28 (1978), pp. 529-547.

—, "Comentario sintáctico", en La oración y sus funciones, Madrid, Arco Libros, 1997, pp. 577-598.

Hernanz Carbó, Ma Lluisa, "El infintivo", en Ignacio Bosque y Violeta Demonte (coords.), Gramática descriptiva de la lengua española, II, Madrid, Espasa Calpe, 1999, pp. $2197-$ 2356.

Hunt, Kellogg, Grammatical Structures Written at Three Grade Levels, Research Report n. 3. Urbana IL, Nacional Council of Teachers of English, 1965.

López García, Ángel, "Relaciones paratácticas e hipotácticas”, en Ignacio Bosque y Violeta Demonte (coords.), Gramática descriptiva de la lengua española, III, Madrid, Espasa Calpe, 1999, pp. 3507-3548.

Katzenberger, Irit, "The development of clause packaging in spoken and written texts", Journal of Pragmatics, 36/10 (2004), pp. 1921-1948.

Lyons, John, Introduction to Theoretical Linguistics, London NY, Cambridge Univ. Press, 1968.

Masi, Silvia, "The Literature of Complexity”, en Lavinia Barbaresi (ed.), Complexity in Language and Text, Pisa, Edizioni Plus/Università di Pisa, 2003, pp. 117-146.

Mavron, Irini, "Precisión lingüística y complejidad sintáctica", Revista Nebrija de lingüística aplicada, 14 (2013). Edición en línea. Último acceso: 26 de abril de 2016 http://www. nebrija.com/revista-linguistica/complejidad-sintactica-y-discurso-academico-parametros-gramaticales-en-la-produccion-escrita-de-estudiantes-universitarios. 
Meneses, Alejandra y Maili Ow, “Género discursivo, sintaxis y lenguaje académico: dimensiones comunicativas y cognitivas del desarrollo tardío del lenguaje", Didáctica, Lengua y Literatura, 24 (2012), pp. 233-247.

Meneses, Alejandra, Maili ow y Ricardo Benítez, "Complejidad sintáctica: ¿modalidad o tipo textual? Estudio de caso de producciones textuales de estudiantes de $5^{\circ}$ básico", Onomazein, 25/1 (2012), pp. 65-93.

Montolío Durán, Estrella, "Las construcciones condicionales" en Ignacio Bosque y Violeta Demonte (coords.), Gramática descriptiva de la lengua española, III, Madrid, Espasa Calpe, 1999, pp. 3643-3738.

Moya Corral, Juan Antonio, Los mecanismos de interordinación: a propósito de pero y aunque, Granada, Universidad de Granada, 1996.

—, "Notas para una caracterización sintáctica de la interordinación", en Luis Santos Río (ed.), Palabras, norma, discurso: en memoria de Fernando Lázaro Carreter, Salamanca, Ediciones Universidad de Salamanca, 2005, pp. 869-880.

Muse, Cecilia Elena y Darío Daniel Delicia, "Complejidad sintáctica y discurso académico", Revista Nebrija de lingüistica aplicada, 14 (2013). Edición en línea. Último acceso: 26 de abril de 2016 http:/www.nebrija.com/revista-linguistica/complejidad-sintactica-y-discursoacademico-parametros-gramaticales-en-la-produccion-escrita-de-estudiantes-universitarios

Narbona Jiménez, Antonio, "Sintaxis del español coloquial: algunas cuestiones previas", en Antonio Briz y otros (eds.), Pragmática y gramática del español hablado. Actas del II Simposio sobre análisis del discurso oral. Valencia, Pórtico, 1996, pp. 157-175.

Nir, Bracha y Ruth Berman, "Complex Syntax as a Window on Contrastive Rhetoric", Journal of Pragmatics, 42/3 (2010), pp. 744-765.

Pastor Pérez, Lluis, Escritura sexy, Barcelona, Editorial UOC, 2008.

Pérez Saldanya, Manuel, "El modo en las subordinadas relativas y adverbiales", en Ignacio Bosque y Violeta Demonte (coords.), Gramática descriptiva de la lengua española, II, Madrid, Espasa Calpe, 1999, pp. 3253-3322.

Porto Dapena, Jesús, El complemento circunstancial, Madrid, Arco Libros, 1993.

RAE, Nueva Gramática de la Lengua Española, Madrid, Espasa, 2009.

Rojo Sánchez, Guillermo, Cláusulas y oraciones. Anejo 14 a la revista Verba. Santiago de Compostela, Univ. de Santiago de Compostela, 1978.

Torres González, Antonia N., Madurez sintáctica en estudiantes no universitarios de la zona metropolitana de Tenerife, La Laguna, Servicio de publicaciones de la ULL, 1993. Tesis doctoral.

—, "Índices primarios de madurez sintáctica en escolares de Tenerife", Reale, 2 (1994), pp. 115-126.

—, "Complejidad sintáctica en escritores de las Islas Canarias", Reale, 8 (1997), pp. 105-125.

Véliz, Mónica, Evaluación de la madurez sintáctica en el discurso escrito, Concepción, Universidad de Concepción, 1986. Tesis doctoral.

—, "Evaluación de la madurez sintáctica en el discurso escrito", RLA, 26 (1988), pp. 105-141.

—, "Complejidad sintáctica y modos del discurso", Estudios Filológicos, 34 (1999), pp. 181-192.

—, "Procesamiento de estructuras sintácticas complejas en adultos mayores y adultos jóvenes”, Estudios Filológicos, 38 (2004), pp. 65-81. 